\title{
Kanserli Çocuklarda Febril Nötropeni Ataklarının İncelenmesi
}

\author{
Ersin Töret", Tuba Hilkay Karapınar, Muhammet Bulut, Ahu Aksay, Yılmaz Ay, Yeșim Oymak, ilker \\ Devrim, Dilek Güneș İnce
}

DOI: $10.17944 /$ mkutfd.489213

Ersin Töret": Uzm. Dr., SBÜ Dr. Behçet Uz Çocuk Hastalıkları ve Cerrahisi Eğitim ve Araștırma Hastanesi, Cocuk Hematoloji-0nkoloji Kliniăi, İzmir Eposta: drersintoret@hotmail.com

ORCID iD: https://orcid.org/0000-0002-6379-8326

Tuba Hilkay Karapınar: Doç. Dr., SBÜ Dr. Behçet Uz Cocuk Hastalıkları ve Cerrahisi Eğitim ve Araștırma Hastanesi, Çocuk Hematoloji-0nkoloji Kliniği, İzmir Eposta: thkarapinar@yahoo.com

ORCID iD: https://orcid.org/0000-0002-4714-332X

Muhammet Bulut: Arș. Gör. Dr., SBÜ Dr. Behçet Uz Cocuk Hastalıkları ve Cerrahisi Eğitim ve Araștırma Hastanesi, Çocuk Hematoloji-Onkoloji Kliniği, İzmir Eposta: dr.mhbulut@gmail.com

ORCID iD: https://orcid.org/0000-0002-5963-1267

Ahu Aksay: Uzm. Dr., SBÜ Dr. Behcet Uz Cocuk Hastalıkları ve Cerrahisi Eğitim ve Araștırma Hastanesi, İzmir

Eposta: ahukara01@hotmail.com

ORCID iD: https://orcid.org/0000-0002-5233-0285

Yılmaz Ay: Doç. Dr., SBÜ Dr. Behçet Uz Çocuk Hastalıkları ve Cerrahisi Eğitim ve Araștırma Hastanesi, Çocuk Hematoloji-0nkoloji Kliniği, İzmir Eposta: dryilmazay@yahoo.com

ORCID iD: https://orcid.org/0000-0002-1693-7143

Yeșim Oymak: Doç. Dr., SBÜ Dr. Behçet Uz Çocuk Hastalıkları ve Cerrahisi Eğitim ve Araștırma

Hastanesi, Cocuk Hematoloji-Onkoloji Kliniği, İzmir Eposta: yesimoymak@hotmail.com

ORCID iD: https://orcid.org/0000-0002-6908-8309

illker Devrim: Prof. Dr., SBÜ Dr. Behçet Uz Çocuk Hastalıkları ve Cerrahisi Eğitim ve Araștırma Hastanesi, İzmir

Eposta: ilkerdevrim2003@yahoo.com ORCID iD: https://orcid.org/0000-0002-6053-8027

Dilek Güneș İnce: Prof. Dr. SBÜ Dr. Behçet Uz Çocuk Hastalıkları ve Cerrahisi Eğitim ve Araștırma Hastanesi, Çocuk Hematoloji-0nkoloji Kliniği, İzmir Eposta: dr.dilek.ince@gmail.com

ORCID iD: https://orcid.org/0000-0002-7914-7886

\section{Bildirimler/Acknowledgement}

Yazarlar bu makale ile ilgili herhangi bir çıkar catıșması bildirmemișlerdir.

The authors declare that they have no conflict of interests regarding content of this article.

Yazarlar bu makale ile ilgili herhangi bir finansal destek bildirmemișlerdir.

The Authors report no financial support regarding content of this article.

Geliș/Received: 28.11.2018

Kabul/Accepted: 05.03.2019

e-ISSN: 2149-3103

Web: http://dergipark.gov.tr/mkutfd
Öz

Kanserli Çocuklarda Febril Nötropeni Ataklarının İncelenmesi

Giriș: Kanser nedeniyle verilen tedavilerin en önemli yan etkilerinden febril nötropeni morbidite ve mortalitenin en önemli nedenidir. Amerika Enfeksiyon Hastalıkları Derneği tarafından mevcut nötropeninin yedi günden uzun sürmesinin beklenmesi ve derin nötropeni (mutlak nötrofil sayısı <100/mm3) gibi yüksek risk özelliği olarak kabul edilmektedir. Febril nötropeni atağı sırasında acil yaklașım geniș spektrumlu antipsödomonal etkinliği olan antibiyoterapinin intravenöz yolla en kısa sürede hastaya uygulanmasıdır. Bu çalıșma üçüncü basamak hizmet veren bir hastanenin 27 aylık dönemde kanserli çocukların febril nötropeni ataklarını incelemeyi amaçlamıștır.

Gereç ve Yöntem: 0cak 2012 ile Mart 2014 tarihleri arasında hematolojik veya solid organ kanseri nedeniyle tedavi edilen olgularda gelișen febril nötropeni atakları retrospektif olarak dosyalarından incelendi. Febril nötropeni; mutlak nötrofil sayısının 500/mm3 altında olması veya 500-1000/ mm3 arasında olup 48 saat içinde 500/mm3 altına düșmesi beklenen durumlara eșlik eden koltuk altından bir kez $38,5^{\circ} \mathrm{C}$ ölçülen veya bir saat boyunca $38^{\circ} \mathrm{C}$ üzerinde seyreden veya dört saatlik süreçte iki kez $38^{\circ} \mathrm{C}$ üzerinde ölçülen ateș varlığı olarak tanımlandı.

Bulgular: Ortalama yașı 7,1 \pm 5,3 yıl olan 48 hastanın 131 febril nötropeni atağı retrospektif olarak incelendi. Hasta grubunun \%75'ini lösemi tanılı olgular olușturmaktaydı. Ataklar sırasında ilk 24 saatte \%69'unun ateș kontrolü sağlandı. Kan veya kateter kültüründe üreme atakların \%36'sında, üremelerin \%64'ünde ise gram negatif bir bakteri saptandı. Hastalara ampirik olarak bașlanan piperasilin-tazobaktam atakların \%32'sinde tedavi için yeterli oldu. Destek amacıyla atakların \%19'unda granülosit koloni stimüle edici faktör uygulandı.

Tartıșma: Kanserli çocuklarda kemoterapi sonrasında gelișen kemik iliği baskılanması veya bașka nedenlerle kemik iliğinin çalışmadığı durumlarda hastaların morbidite ve mortalitesini en aza indirmek için geniș spektrumlu antibiyoterapi en kısa sürede bașlanmalıdır.

Anahtar Kelimeler: Çocukluk çağı, febril nötropeni, kanser, lösemi

\section{Abstract \\ Evaluation of Febrile Neutropenic Episodes of Childhood Malignancies}

Introduction: The most important side effect of therapeutics given for cancer treatment is febrile neutropenia. Neutropenia expected to be longer than seven days and severe neutropenia (absolute neutrophil count <100/mm3) especially in hematologic cancers and solid organ tumors that show bone marrow dissemination is accepted as a high-risk feature by American Infectious Disease Society. The emergent approach to a febrile neutropenia attack is to give intravascular antibiotherapy within the shortest time possible. We aimed to evaluate the febrile neutropenia attacks of pediatric cancer patients in a tertiary referral hospital during a 27-month period.

Methods: Febrile neutropenia attacks of cases treated between January 2012 and March 2014 were investigated retrospectively from the patient files. Febrile neutropenia was defined as absolute neutrophil count below $500 / \mathrm{mm} 3$ or between $500-1000 / \mathrm{mm} 3$ but expected to fall below $500 / \mathrm{mm} 3$ within 48 hours in the presence of fever of 38,50C with single axillary measurement or above $380 \mathrm{C}$ for one hour or two measurements above $380 \mathrm{C}$ within 4 hours. Results: 0ne hundred thirty-one febrile neutropenia attacks of 48 patients were investigated retrospectively. Fever was managed within 24 hours in 69\% patients. Peripheral and catheter-drawn blood cultures showed bacterial growth in 36\% of the attacks, $64 \%$ of these growths being gram negative bacteria. Empirical treatment with piperacilin-taxobactam was observed to be efficient in $32 \%$ of the attacks. As a supportive treatment, cases received G-CSF in 19\% of the attacks.

Conclusion: In order to, minimize morbidity and mortality of febrile neutropenia, wide spectrum antibiotics must be given intravenously within the shortest time possible in pediatric cancers.

Keywords: Childhood, febrile neutropenia, cancer, leukemia 


\section{GİRIŞ}

Çocukluk yaş grubu kanserlerinde yıllar içinde gelişen tedaviler sağ kalım şansını belirgin artırırken tedavilerin neden olduğu kemik iliği baskılanması sonucu gelişen febril nötropeniye (FN) bağlı morbidite ve mortalite halen önemini korumaktadır $(1,2)$. Febril Nötropeni; mutlak nötrofil sayısının (MNS) 500/mm3 altında olması veya 500$1000 / \mathrm{mm} 3$ arasında olup 48 saat içinde $500 / \mathrm{mm} 3$ altına düşmesi beklenen durumlara eşlik eden koltuk altından bir kez 38,50C ölçülen veya bir saat boyunca 380C üzerinde seyreden veya dört saatlik süreçte iki kez $380{ }^{\circ} \mathrm{C}$ üzerinde ölçülen ateş olarak tanımlanır $(3,4)$.

Hastalara acil geniş spektrumlu intavenöz antibiyoterapinin hastane yatışı yapılarak başlama hedefi FN mortalitesini \%5'in altına indirmiștir (5). Amerika Enfeksiyon Hastalıkları Derneği (AEHD (IDSA)) kılavuzuna FN'li çocuk hastalarda yüksek risk kriterleri; derin nötropeni (MNS<100/mm3), nötropeninin yedi günden daha uzun sürmesinin beklenmesi, kanserin lösemi olması, eşlik eden şok, hipotansiyon, solunum sıkıntısı veya nörolojik bulgu olması, hastada böbrek, karaciğer veya kalp yetmezliği gelişmiş olması, tifilit, pnömoni veya ağır mukozit varlığı, öncesinde mantar enfeksiyonu geçirmiş olmak ve son olarak altta yatan kanserin remisyonda olmaması veya progresif olması olarak sıralanmıştır (Tablo 1) (1).

$\mathrm{Bu}$ çalışma lösemi veya solid organ kanseri nedeniyle kemoterapi verilerek kemik iliği baskılanan çocuklarda FN ataklarını irdelemeyi amaçlamıştır.

Tablo 1. Amerikan Enfeksiyon Hastalıkları Derneği kılavuzunda yer alan kanserli çocuk hastalarda yüksek risk özellikleri (1)

Derin nötropeni $\left({ }^{*} \mathrm{MNS}<100 / \mathrm{mm}^{3}\right)$

Nötropeninin yedi günden daha uzun sürmesinin beklenmesi

Kanserin lösemi veya kemik iliği yayılımı olan solid organ kanseri olması

Eşlik eden şok, hipotansiyon, solunum sıkıntısı veya nörolojik bulgu olması

Böbrek, karaciğer veya kalp yetmezliği gelişmiş olması

Tifilit, pnömoni veya ağır mukozit varlığı,

Öncesinde mantar enfeksiyonu geçirmiş olmak ve son olarak

Altta yatan kanserin remisyonda olmaması veya progresif olması

*MNS: Mutlak nötrofil sayısı

\section{GEREÇ VE YÖNTEM}

Çocuk Hematoloji-Onkoloji Kliniği tarafından lösemi veya solid organ kanseri nedeniyle tedavisi devam eden veya kemoterapisi tamamlanmış ancak tedavi ilişkili kemik iliği baskılanması devam eden hastaların FN atak kabul edilen başvurularının dosya kayıtları retrospektif olarak in- celendi. İnceleme Ocak 2012 ile Mart 2014 tarihleri arasını kapsadı. Hastaların demografik özellikleri (yaş, cins, tanı gibi) ve atak sırasındaki öykü, klinik, laboratuvar ve tedavi özelliklerine dosya kayıtlarından ulaşıldı.

İstatiksel değerlendirme SPSS 17.0 programı kullanılarak yapıldı. Hastaların ve FN atakların özellikleri tanımlayıcı istatistik kullanılarak irdelendi.

\section{BULGULAR}

Kırk sekiz (32 erkek, 16 kız) hastanın 131 FN atağı incelendi. Hastaların ortalama yaşı $7,1 \pm 5,3$ yıl ( 3 ay - 17 yıl) olarak hesaplandı. Altta yatan kanser dağılımında 31'i (\%65) akut lösemi (25 lenfoblastik, 6 myeloid), 15’i (\%31) solid organ kanseri (yedi hepatoblastoma, ikişer wilms tümörü ve nöroblastom, birer osteosarkom, ewing sarkom, rabdomyosarkom, medullublastom) ve 2'si (\%4) lenfomaydı. Febril nötropenik atak sırasında kültürler alındıktan sonra rutin piperasilin-tazobaktam başlandı. Atakların 98'i (\%75) lösemi tanılı olgularda izlenirken, $87 \mathrm{FN}$ atağında ise yüksek risk özelliği görüldü. Febril nötropeni atağı geçiren 31 lösemi tanılı olgunun 27'si atakların 88'ini tedavinin indüksiyon-konsolidasyon döneminde geçirdi. İlk 24 saatte 69 (\%53), 72 saatte ise 94 (\%72) FN atağında hastaların ateş yüksekliği kontrol altına alınırken, 22 atakta (\%17) 5 günden uzun süren ateş saptandı (Grafik 1).

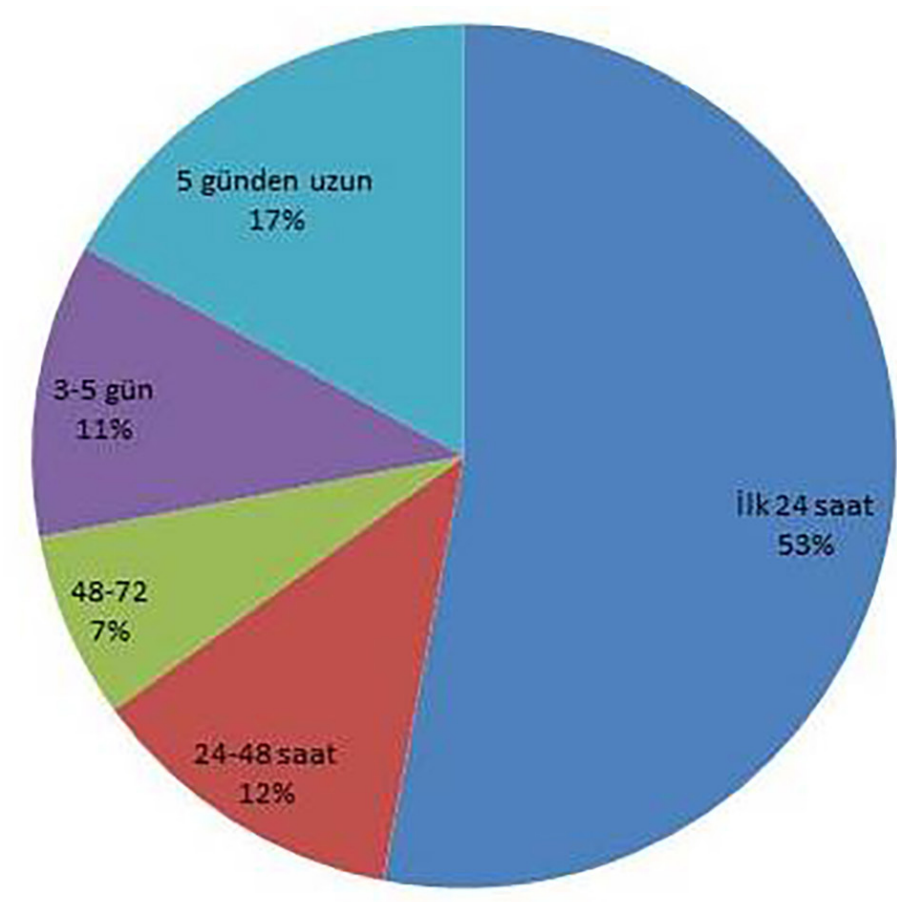

Grafik 1. Atakların ateş kontrol sürelerinin dağılımı 
Febril nötropeni ataklarında 47'sinde (\%36) kan veya kateter kültürde üreme saptandı. Saptanan etkenlerden 42'si bakteri (30'u gram negatif, 12'si gram pozitif) ve 5'i mantardı. Gram negatif Psödomonas ve Klebsella alt tipleri, gram pozitif koagulaz negatif stafilokok ve fungal etken olarak Candida parapsilosis en sık üretildi. Hastalara ampirik olarak başlanan piperasilin-tazobaktam 42 atakta (\%32) tedavi için yeterli olurken, uzayan ateş, yüksek risk özellikleri ve saptanabilen etkenlere yönelik tedavilerle 89 atakta (\%68) çoklu antibiyotik tedavisi uygulandı. Yirmi beş atak (\%19) sırasında olgulara destek tedavi amacıyla granülosit koloni stimüle edici faktör (G-CSF), 4 atak (\%3) için ise aferez granulosit süspansiyonu uygulandı. İki hasta FN atağı sırasında kaybedildi. Olgulardan biri akut myelositer lösemi tanılı ve atağın 22. gününde, diğeri hepatoblastoma tanılı ve atağın 9. gününde pnömoni nedeniyle kaybedildi.

\section{TARTIŞMA}

Febril nötropenik ataklar çocukluk çağı kanser tedavilerinde morbidite ve mortaliteyi artıran en önemli komplikasyon olmaya devam etmektedir. Febril nötropeni atakları çocukluk yaş grubunda bu çalışmada da saptandığı üzere çoğunlukla lösemi tedavisinin indüksiyon-konsolidasyon döneminde saptanır (6). Ampirik geniş spektrumlu antibiyoterapiye en kısa sürede bașlanması ve nadir olgular dışında hastaların yatırılarak intravenöz tedavi yapılması en temel yaklaşımdır $(4,7,8)$. Ülkemizde 24 merkezin katıldığı $829 \mathrm{FN}$ atağın irdelendiği çalışmada \%32 atakta kültür üremesi saptanırken, \%21 oranda bakteriyemi raporlandı (9). Aslan ve ark. (10) çalışmasında ise 811 atak incelendiğinde \%28'inde kan kültüründe bir etken belirlendi. Bu iki çalışmada gram pozitif bakteri üremesi daha fazla görülürken, Gudiol ve ark. (11), Kar ve ark. (12), bizim çalışmamızda gram negatif bakteri üremesi daha fazla saptandı. Geleneksel ampirik tedavi antipsödomonal beta-laktam bir antibiyotik ile aminoglukozidin kombine tedavisi şeklinde yapılmaktadır. Üçüncü ve 4 . kuşak antipsödomonal etkili geniş spektrumlu antibiyotiklerin kullanıma girmesi tekli tedavilerin tercih edilmesinin önünü açmıştır $(13,14)$. Bu çalışmada tekli tedavi atakların \%32'sinde yeterli olduğu belirlenirken atakların \%68'inde iki veya daha fazla antibiyotik ve bazı ataklarda ampirik başlanan antibiyotiklerin değiştirilmesi gerekti. Febril nötropenik atakta mortalite ampirik geniş spektrumlu tedavilerin kullanılmasıyla \%1-3 arasında görülmektedir $(15,16)$. Bu çalışmada da iki olgu atak sırasında kaybedildi. Kaybedilen akut myeloid lösemi hastasında E. Coli izole edilirken diğer olguda (hepatoblastom) kültür üremesi olmadı.

Kemoterapi sonrasında veya başka nedenlerle kemik iliğinin çalışmadığı veya baskılandığı durumlarda hastaların morbidite ve mortalitesini en aza indirmek için intravenöz geniş spektrumlu antibiyoterapi en kısa sürede başlan- malıdır. Antibiyoterapiye rağmen yüksek risk faktörleri ve hastaya özgü durumlar önemini korumaktadır.

\section{Kaynaklar}

1. Freifeld AG, Bow EJ, Sepkowitz KA, Boeckh MJ, Ito JI, Mullen CA et al.; Infectious Diseases Society of America. Clinical practice guideline for the use of antimicrobial agents in neutropenic patients with cancer: 2010 update by the infectious diseases society of america. Clin Infect Dis. 2011 Feb 15;52(4):e56-93.

2. Phillips RS, Wade R, Lehrnbecher T, Stewart LA, Sutton AJ. Systematic review and meta-analysis of the value of initial biomarkers in predicting adverse outcome in febrile neutropenic episodes in children and young people with cancer. BMC Med. 2012 Jan 18;10:6. doi: 10.1186/1741-7015-10-6.

3. Pizzo PA, Robichaud KJ, Wesley R, Commers JR. Fever in the pediatric and young adult patient with cancer. A prospective study of 1001 episodes. Medicine (Baltimore). 1982 May;61(3):153-65.

4. Hann I, Viscoli C, Paesmans M, Gaya H, Glauser M. A comparison of outcome from febrile neutropenic episodes in children compared with adults: results from four EORTC studies. International Antimicrobial Therapy Cooperative Group (IATCG) of the European Organization for Research and Treatment of Cancer (EORTC). Br J Haematol. 1997 Dec;99(3):580-8.

5. Maxwell RR, Egan-Sherry D, Gill JB, Roth ME. Management of chemotherapy-induced febrile neutropenia in pediatric oncology patients: A North American survey of pediatric hematology/ oncology and pediatric infectious disease physicians. Pediatr Blood Cancer. 2017 Dec;64(12).

6. Crawford J, Dale DC, Lyman GH. Chemotherapy-induced neutropenia: risks, consequences, and new directions for its management. Cancer. 2004 Jan 15;100(2):228-37.

7. Boragina M, Patel H, Reiter S, Dougherty G. Management of febrile neutropenia in pediatric oncology patients: a Canadian survey. Pediatr Blood Cancer. 2007 May;48(5):521-6.

8. Delebarre M, Tiphaine A, Martinot A, Dubos F. Risk-stratification management of febrile neutropenia in pediatric hematologyoncology patients: Results of a French nationwide survey. Pediatr Blood Cancer. 2016 Dec;63(12):2167-2172.

9. Kebudi R, Vural S, Gürler N, Anak S, (tüm katılan merkezler adına). Febril nötropenik kanserli çocuklarda klinik ve mikrobiyolojik kanıtlanmış infeksiyonlar ve infeksiyon etkenleri. İçinde: Kebudi R, Anak S, Vural S (editörler). Pediatrik hematoloji-onkoloji merkezlerinde febril nötropeni tanı ve tedavi uygulamaları, çalışmaları ve sonuçları kitabı. İstanbul: İstanbul Üniversitesi; 2004.p.100-5.

10. Aslan S, Citak EC, Yis R, Degirmenci S, Arman D. Bacterial spectrum and antimicrobial susceptibility pattern of bloodstream infections in children with febrile neutropenia: experience of single center in southeast of Turkey. Indian J Microbiol. 2012 Jun;52(2):203-8.

11. Gudiol C, Bodro M, Simonetti A, Tubau F, González-Barca E, Cisnal $\mathrm{M}$ et al.; Changing aetiology, clinical features, antimicrobial resistance, and outcomes of bloodstream infection in neutropenic 
cancer patients. Clin Microbiol Infect. 2013 May;19(5):474-9.

12. Kar YD, Özdemir ZC, Bör Ö. Evaluation of febrile neutropenic attacks of pediatric hematology-oncology patients. Turk Pediatri Ars. 2017 Dec 1;52(4):213-220.

13. Vandercam B, Gérain J, Humblet Y, Ferrant A, Wauters G, Moreau $\mathrm{M}$ et al.; Meropenem versus ceftazidime as empirical monotherapy for febrile neutropenic cancer patients. Ann Hematol. 2000 Mar;79(3):152-7.

14. Erbey F, Bayram I, Yilmaz S, Tanyeli A. Meropenem monotherapy as an empirical treatment of febrile neutropenia in childhood cancer patients. Asian Pac J Cancer Prev. 2010;11(1):123-6.

15. Hakim H, Flynn PM, Knapp KM, Srivastava DK, Gaur AH. Etiology and clinical course of febrile neutropenia in children with cancer. J Pediatr Hematol Oncol. 2009 Sep;31(9):623-9.

16. Reinecke J, Lowas S, Snowden J, Neemann K. Blood Stream Infections and Antibiotic Utilization in Pediatric Leukemia Patients With Febrile Neutropenia. J Pediatr Hematol Oncol. 2018 Aug 8. 